\title{
Animal Models Service Shared Resource
}

National Cancer Institute

\section{Source}

National Cancer Institute. Animal Models Service Shared Resource. NCI Thesaurus. Code C39322.

The Animal Models Service Shared Resource is primarily dedicated to the production, development and characterization of biomedical relevant animal models and species for cancer research including transgenic, knockout, mutant, etc. experimental animal lines. Strains, species and methods are considered according to particular Cancer Center investigators' requirements. 